\title{
Expression of PPAR $\gamma$ and PTEN in human colorectal cancer: An immunohistochemical study using tissue microarray methodology
}

\author{
MAO SONG LIN ${ }^{1}$, JUN XING HUANG ${ }^{2}$, WEI CHANG CHEN ${ }^{3}$, BAO FENG ZHANG ${ }^{4}$, \\ JING FANG ${ }^{4}$, QIONG ZHOU ${ }^{4}$, YING HU ${ }^{4}$ and HENG JUN GAO ${ }^{4,5}$ \\ Department of ${ }^{1}$ Gastroenterology and ${ }^{2}$ Oncology, Taizhou People's Hospital, Taizhou, Jiangsu 225300; \\ ${ }^{3}$ Department of Gastroenterology, the First Hospital Affiliated to Soochow University, Suzhou, Jiangsu 215006; \\ ${ }^{4}$ National Engineering Center for Biochip at Shanghai; ${ }^{5}$ Institute of Digestive Disease, \\ Tongji Hospital Affiliated to Tongji University, Shanghai 201203, P.R. China
}

Received July 7, 2011; Accepted August 31, 2011

DOI: $10.3892 / \mathrm{ol} .2011 .414$

\begin{abstract}
Although aberrations of peroxisome proliferatoractivated receptor $\gamma(\operatorname{PPAR} \gamma)$ and phosphatase and tensin homolog (PTEN) expression have been identified in several other cancer types, certain previous studies have revealed that PPAR $\gamma$ is abundant in normal and malignant tissue in the colon. The question of whether aberrant PTEN is involved in the initial stage or is a later event during colorectal carcinogenesis remains controversial. Relatively few studies have focused on the correlation of expression of PPAR $\gamma$ and PTEN in various tissues. In the present study, paraffin-embedded blocks from 139 patients with CRC, 18 adenomatous polyps and 50 paired paracancerous benign mucosas were selected and analysed in 4 tissue microarray (TMA) blocks comprising 104, 72, 130 and 54 cores, respectively. Expression of PPAR $\gamma$ and PTEN was examined using immunohistochemical staining on TMAs. There were no significant differences in the expression of PPAR $\gamma(\mathrm{P}=0.055)$ and PTEN $(\mathrm{P}=0.100)$ between the colorectal cancers, adenomas and paracancerous mucosas. However, correlations of PPAR $\gamma$ expression with clinical stage $(\mathrm{P}=0.004)$ and $\mathrm{PTEN}$ expression with histological grade $(\mathrm{P}=0.006)$ and distant metastasis $(\mathrm{P}=0.015)$ were demonstrated in the CRC specimens. Although the differences in PPAR $\gamma$ and PTEN protein expression in human colorectal cancer may not be considered as early diagnostic markers, our results indicate that $\mathrm{CRCs}$ with a low expression or deletion of PTEN may progress towards invasion and even metastasis; thus, PTEN may have potential as a prognostic marker in human CRC.
\end{abstract}

Correspondence to: Dr Maosong Lin, Department of Gastroenterology, Taizhou People's Hospital, 210 Yingchun Road, Taizhou, Jiangsu 225300, P.R. China

E-mail:1ms0605@163.com

Key words: peroxisome proliferator receptor $\gamma$, phosphatase and tensin homolog, tissue microarray, immunohistochemistry, colorectal cancer

\section{Introduction}

Colorectal cancer (CRC), one of the most common malignant neoplasms in Western countries, has become increasingly frequent in China, mostly due to the improvement of living standards and alteration of eating habits. Although overall survival has climbed to approximately $65 \%$ after 5 years, partly due to the development of systematic therapeutic modalities in past decades, one-third of advanced patients succumb to progressive disease (1). Mounting evidence has demonstrated that several genetic alterations are involved in the carcinogenetic process of CRC (2). Identification of multiple cancer-associated molecules may further our knowledge of the gene regulation throughout the tumorigenetic process in human CRC.

Peroxisome proliferator-activated receptor $\gamma(\operatorname{PPAR} \gamma)$ is a member of the steroid receptor superfamily and belongs to the ligand-activated transcription factors. PPAR $\gamma$ forms a heterodimer with retinoid X-receptor $\alpha$ in the presence of its ligands, such as polyunsaturated fatty acids and arachidonic acid derivatives, following which it regulates the expression of target genes. In addition to functioning as a significant regulator of adipocyte differentiation and fatty acid metabolism, PPAR $\gamma$ was found to be correlated with several types of cancer, including CRC $(3,4)$. Although aberrations of PPAR $\gamma$ expression have been observed in several other cancer types, previous studies revealed that PPAR $\gamma$ was abundant in normal and malignant tissue in the colon $(5,6)$, where its function is largely unknown. Moreover, the roles of PPAR $\gamma$ in various stages of CRC are also poorly understood. One recent study demonstrated that activation of PPAR $\gamma$ inhibited cell growth and induced cell differentiation in human colorectal cancer through several pathways involving the induction of PTEN over-expression (7). PTEN undergoes genetic or epigenetic inactivation in many malignancies including colorectal cancer $(8,9)$. The role of the lipid phosphatase activity of PTEN as a negative regulator of the cytoplasmic phosphatidylinositol3-kinase/Akt pathway is well known. However, certain studies have also revealed that PTEN may relocate to the nucleus and indicate an additional modulation mechanism $(10,11)$. Additionally, the question of whether aberrant PTEN is 
Table I. Characteristics of study population.

\begin{tabular}{lccccrr}
\hline & \multirow{2}{*}{$\begin{array}{c}\text { Age at enrolment } \\
\text { (mean } \pm \text { SD) }\end{array}$} & \multicolumn{2}{c}{ Gender } & & \multicolumn{2}{c}{ Location } \\
\cline { 3 - 4 } & & Male & Female & & Colon & Rectum \\
\hline Cancer $(\mathrm{n}=139)$ & $54 \pm 28$ & 84 & 55 & & 85 & 54 \\
Adenoma $(\mathrm{n}=18)$ & $48 \pm 12$ & 11 & 7 & 12 & 6 \\
Normal $(\mathrm{n}=50)$ & $55 \pm 27$ & 35 & 15 & 32 & 18 \\
\hline
\end{tabular}

involved in the initial stages or is a later event in CRC remains controversial.

To date relatively few studies have focused on the correlation of expression of PPAR $\gamma$ and PTEN in various tissues. In this study, we examined the protein expression of PPAR $\gamma$ and PTEN using immunohistochemical (IHC) staining on tissue microarray (TMA) in CRC, adenoma and corresponding normal para-cancerous colorectal tissues and explored their potential clinical significance.

\section{Materials and methods}

Materials and patients. Formalin-fixed and paraffinembedded colorectal cancer tissues, adenomatous polyps and paraneoplastic normal tissue specimens were obtained from the archives of the Department of Gastroenterology, the First Affiliated Hospital of Soochow University and the National Engineering Center for Biochip in Shanghai, China. Demographic and clinical data were collected retrospectively (Table I). A total of 139 patients comprising 84 males and 55 females (age range 54 \pm 28 ), with CRC (colon cancer, 85; rectal cancer, 54) were included in this study. None of the patients had received radiotherapy or chemotherapy prior to surgery. Specimens were viewed by one pathologist (Dr Jing Fang). CRC tissues were diagnosed, staged and graded according to the guidelines on the national diagnosis and treatment of CRC. In these cohort CRC patients, the median age was 54. The incidence of CRC in China demonstrates a younger tendency. Therefore, in our study, we chose 54 years as a cut-off value to separate patients into two groups. In regard to the degree of cancer cell differentiation, 27 cases were well-differentiated, 81 were moderately differentiated and 31 were poorly differentiated. Lymph node metastases were observed in 50 patients and distant metastases were observed in 23 patients, 13 patients had missing parameters. With the exception of 10 patients with unclear stage parameters, the ramaining 129 patients were classified into Dukes' A (25 cases), B (44 cases), C (37 cases) and D (23 cases), according to the clinical stages. The 18 adenomatous polyp specimens were removed by colonoscopy and the 50 para-cancerous normal tissues were resected at least $5 \mathrm{~cm}$ away from the corresponding cancer tissues. Written informed consent was obtained from each patient according to the institutional regulations.

Reagents. Primary rabbit polyclonal antibodies against human PPAR $\gamma$ and PTEN were obtained from Santa Cruz Biotechnology (Santa Cruz, CA, USA). The EnVision+ ${ }^{\mathrm{TM}}$ goat-anti rabbit kit was a product of GenTech company.
Construction and sectioning of tissue microarray. The TMAs were assembled using a manual tissue arrayer. In brief, the CRCs, adenomas and normal tissues were embedded in paraffin blocks and 5- $\mu \mathrm{m}$ sections stained with hematoxylineosin (HE) were obtained to select representative areas for biopsies. The selected donor cores (diameter 1.0 or $1.5 \mathrm{~mm}$ ) were extracted from areas of individual donor paraffin blocks and precisely arrayed into a new recipient block with a custom-built instrument (Beecher Instruments, Silver Spring, MD, USA). Tissue specimens from 139 CRCs, 18 adenomatous polyps and 50 para-cancerous benign mucosas were arranged in 4 recipient paraffin blocks. A total of 3 core tissue biopsies were obtained from each specimen. After construction, $4-\mu \mathrm{m}$ slides were cut from these recipient blocks and used in series for IHC staining.

IHC staining to TMA sections. Microarray sections (4- $\mu \mathrm{m})$ were soaked in xylene overnight to remove any adhesive from the tape transfer system. Slides were deparaffinized and rehydrated and antigens were then retrieved by autoclave. Following incubation in $10 \%$ normal goat serum for $20 \mathrm{~min}$ at room temperature, the sections were stained with the primary antibodies at 1:100 dilution overnight at $4^{\circ} \mathrm{C}$. The antibodies used were monoclonal (rabbit antihuman) with PPAR $\gamma$ and PTEN purchased from Santa Cruz Biotechnology Inc. The primary antibodies were further examined using a biotin-free, horseradish peroxidase enzyme-labeled polymer conjugated to anti-rabbit secondary antibodies (GeneTech).

Each of the IHC-stained sections was scored according to the sum of the extension area and intensity (12). Nuclear staining with yellow and/or brown was scored for PPAR $\gamma$, whereas complete cytoplasm staining was assessed for PTEN. The intensities were scored as 0 (negative), + (faint/equivocal), ++ (moderate), and +++ (strong). The immunoreactive areas were categorized as $0(<5 \%),+(5-25 \%),++(26-50 \%),+++$ $(51-75 \%)$ and $++++(>75 \%)$. Combined scores $\geq++$ were considered positive and staining scores $\geq+++$ were regarded as strong positive.

Statistical analysis. Statistical analysis of PPAR $\gamma$ and PTEN stainings and their correlations with clinicopathological variables were carried out using the SPSS program, version 13.0 (SPSS, Inc.). Pearson's $\chi^{2}$ test or Fisher's exact test were applied to compare the staining index and clinicopathological parameters of the two molecules. The significance level was defined as $\mathrm{P}<0.05$.

This study was approved by the Ethics Committee of Soochow University. 

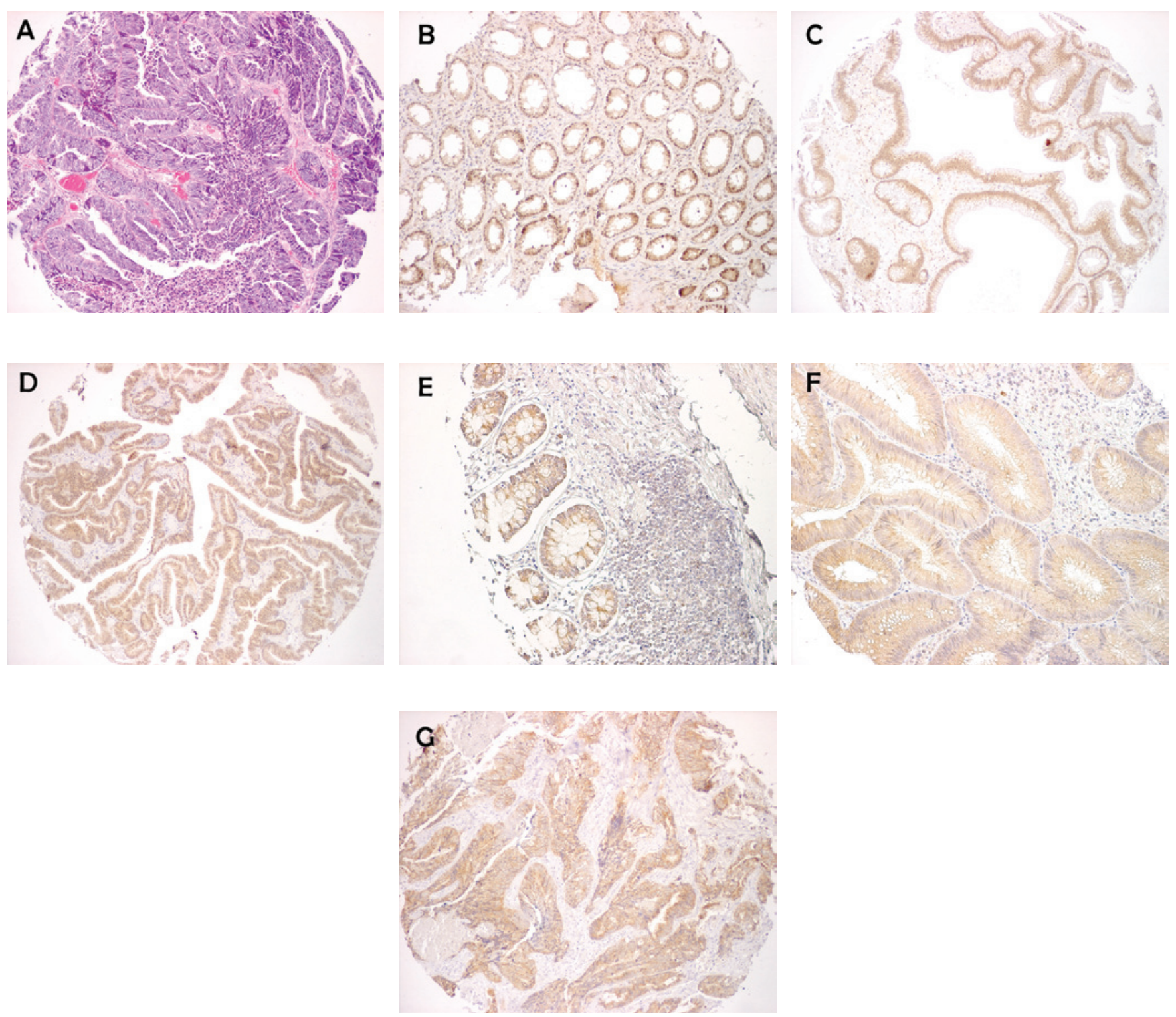

Figure 1. Immunophenotype of the investigated antigens (PPAR $\gamma$ and PTEN) in three colorectal tissues (original magnification, x100). Positive stainings of PPAR $\gamma$ were located in the cell nuclei, while those of PTEN were in the cytoplasm. (A) HE staining of the TMA section of colorectal cancer tissue. (B, C and D) PPAR $\gamma$ expression in benign mucosa, adenomas and cancer tissues. (E, F and G) PTEN expression in benign mucosa, adenomas and cancer tissues, respectively.

\section{Results}

Expression of PPAR $\gamma$ and PTEN in different tissues. The expression of PPAR $\gamma$ protein was mainly located in the cell nucleus, with a minority in the cytoplasm. Positive expression was detected in 125 specimens in 139 CRC tissues, 15 specimens in 18 adenomas and 41 in 50 corresponding normal colorectal tissues, whereas strong positive rates were $25 \%$ (35/139), 17\% (3/18) and 34\% (17/50), respectively (Fig. 1). No significant differences were found among the CRC, adenoma and normal colorectal mucosa regarding IHC staining in our study ( $\mathrm{P}=0.055)$. (Table II). Furthermore, there was also no signifcantly different expression observed between the cancer tissues and their normal paracancerous counterparts following the exclusion of the adenoma data $(\mathrm{P}=0.112)$.

The expression of PTEN protein was commonly observed in the cytoplasm in CRC, adenoma and normal colorectal mucosa. Positive immunostainings were observed in 129 tissues of 139 CRC specimens, 15 of 18 adenomas and 48 in normal colorectal mucosa tissues (Fig. 1). No statistically significant difference was found between these tissue types. ( $\mathrm{P}=0.100)$ (Table II). Similarly, when the cancerous and para-cancerous tissues were isolated, a significantly different expression of PTEN was not observed ( $\mathrm{P}=0.846)$.

We further investigated the relationship between the PPAR $\gamma$ and PTEN, according to our originally conservative plan. Notably, the expression of PPAR $\gamma$ was found to be positively correlated with that of PTEN in this cohort tissue in our study $(\mathrm{r}=0.375, \mathrm{P}=0.000)$.

Correlations between the expression of PPAR $\gamma / P T E N$ and the clinicopathological parameters. The association between the IHC pattern of PPAR $\gamma$ and clinicopathological features including age, gender, histological grade, lymph node and 
Table II. Expression of PPAR $\gamma$ and PTEN in different colorectal tissues.

\begin{tabular}{|c|c|c|c|c|c|c|c|c|c|c|c|}
\hline \multirow{2}{*}{ Groups } & \multirow{2}{*}{ Numbers } & \multicolumn{4}{|c|}{$\operatorname{PPAR} \gamma(\%)$} & \multirow{2}{*}{ P-value ${ }^{a}$} & \multicolumn{4}{|c|}{ PTEN (\%) } & \multirow{2}{*}{ P-value ${ }^{a}$} \\
\hline & & - & $1+$ & $2+$ & $3+$ & & - & $1+$ & $2+$ & $3+$ & \\
\hline Cancer & 139 & $13(9.4)$ & $1(0.7)$ & $90(64.7)$ & $35(25.2)$ & 0.055 & $6(4.3)$ & $4(2.9)$ & $74(53.2)$ & 55 (39.6) & 0.100 \\
\hline Adenoma & 18 & $3(16.7)$ & $0(0.0)$ & $12(66.6)$ & 3 (16.7) & & $1(5.6)$ & $2(11.1)$ & $12(66.7)$ & $3(16.6)$ & \\
\hline Normal & 50 & $7(14.0)$ & $2(4.0)$ & $24(48.0)$ & $17(34.0)$ & & $1(2.0)$ & $1(2.0)$ & $29(58.0)$ & $19(38.0)$ & \\
\hline
\end{tabular}

${ }^{a}$ Tested by $\chi^{2}$ or Fisher's exact test.

Table III. Correlations between the expression of PPAR $\gamma$ or PTEN and the clinicopathological data in the CRC patients.

\begin{tabular}{|c|c|c|c|c|c|c|c|c|c|c|c|}
\hline \multirow{2}{*}{ Clinicopathological data } & \multirow{2}{*}{ Number } & \multicolumn{4}{|c|}{$\operatorname{PPAR} \gamma$} & \multirow{2}{*}{ P-value ${ }^{a}$} & \multicolumn{4}{|c|}{ PTEN } & \multirow{2}{*}{ P-value } \\
\hline & & - & $1+$ & $2+$ & $3+$ & & - & $1+$ & $2+$ & $3+$ & \\
\hline \multicolumn{12}{|l|}{ Age } \\
\hline$<54$ & 45 & 7 & 0 & 26 & 12 & \multirow[t]{2}{*}{0.274} & 3 & 2 & 24 & 16 & \multirow[t]{2}{*}{0.576} \\
\hline$\geq 54$ & 94 & 6 & 1 & 64 & 23 & & 3 & 2 & 50 & 39 & \\
\hline \multicolumn{12}{|l|}{ Gender } \\
\hline Male & 84 & 9 & 1 & 51 & 23 & \multirow[t]{2}{*}{0.647} & 5 & 4 & 45 & 30 & \multirow[t]{2}{*}{0.234} \\
\hline Female & 55 & 4 & 0 & 39 & 12 & & 1 & 0 & 29 & 25 & \\
\hline \multicolumn{12}{|l|}{ Histological grade } \\
\hline Low & 31 & 6 & 0 & 17 & 8 & \multirow[t]{3}{*}{0.165} & 5 & 2 & 18 & 6 & \multirow[t]{3}{*}{0.006} \\
\hline Moderate & 81 & 6 & 0 & 53 & 22 & & 1 & 2 & 43 & 35 & \\
\hline High & 27 & 1 & 1 & 20 & 5 & & 0 & 0 & 13 & 14 & \\
\hline \multicolumn{12}{|l|}{ Lymph-node metastasis } \\
\hline Negative & 89 & 6 & 0 & 59 & 24 & \multirow[t]{2}{*}{0.259} & 3 & 2 & 42 & 42 & \multirow[t]{2}{*}{0.069} \\
\hline Positive & 50 & 7 & 1 & 31 & 11 & & 3 & 2 & 32 & 13 & \\
\hline \multicolumn{12}{|l|}{ Distant metastasis } \\
\hline Negative & 103 & 7 & 1 & 65 & 30 & \multirow[t]{2}{*}{0.175} & 2 & 3 & 58 & 40 & \multirow[t]{2}{*}{0.015} \\
\hline Positive & 23 & 4 & 0 & 16 & 3 & & 4 & 1 & 8 & 10 & \\
\hline \multicolumn{12}{|l|}{ Dukes' stage } \\
\hline $\mathrm{A}$ & 25 & 2 & 0 & 21 & 2 & \multirow[t]{4}{*}{0.004} & 0 & 1 & 12 & 12 & \multirow[t]{4}{*}{0.095} \\
\hline B & 44 & 1 & 0 & 23 & 20 & & 1 & 1 & 23 & 19 & \\
\hline $\mathrm{C}$ & 37 & 5 & 1 & 22 & 9 & & 1 & 1 & 25 & 10 & \\
\hline $\mathrm{D}$ & 23 & 4 & 0 & 16 & 3 & & 4 & 1 & 8 & 10 & \\
\hline
\end{tabular}

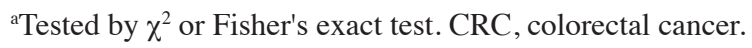

distant metastasis were not statistically significant $(\mathrm{P}>0.05)$. Similarly, there were no significant associations between the expression of PTEN and age, gender, clinical stage and lymph node metastasis. However, PTEN protein expression was found to be correlated with $\mathrm{CRC}$ histological grade $(\mathrm{P}=0.006)$ and distant metastasis $(\mathrm{P}=0.015)$. PPAR $\gamma$ expression was also shown to correlate with clinical stage in this cohort of CRC patients $(\mathrm{P}=0.004)$. (Table III).

\section{Discussion}

Although it has been identified in other cancer cells, including prostate, gastric, pancreatic and lung cancer, but found to be absent from their corresponding benign tissues (13-16), PPAR $\gamma$ was found to be expressed ubiquitously in colorectal epithelial cells and cancer cells by certain authors (17-19). The first problem to be addressed in the study is therefore the exact expression status of PPAR $\gamma$ in various colorectal specimens.

In their study, Mansen et al (17) found that expression levels of PPAR $\gamma$ and PPAR $\beta / \delta$ in colorectal tissues of mice were higher than those in the small intestine, and that the expression of PPAR $\gamma$ was gradually increased from crypt to lumen. Similarly, Fujisawa et al (18) found that PPAR $\gamma$ was expressed highly in human normal colon epithelium and cancer cells. In the present study, our results revealed that PPAR $\gamma$ was highly expressed in three tissues and that no statistically significant 
difference was observed, consistent with the study by Eun et al (19). Therefore, in combination with the results of previous studies and our investigations, we propose that the colorectal basal cells decreased in fissionability and developed differentiated potential followed by the increased expression of PPAR $\gamma$ during the differentiation process. These results demonstrate that, although a variety of gene aberrations such as deletion of APC and P53 and activation of RAS occur during the progression of CRC, the protein expression of PPAR $\gamma$ may exhibit no marked change, indicating that the variation of PPAR $\gamma$ protein expression may not be involved in the progression of CRC. However, whether other patterns of PPAR $\gamma$ aberrations such as mutation, rearrangement or post-translational modification are involved in the pathogenesis of CRC is poorly understood. Therefore, together with other studies, we propose that PPAR $\gamma$ expression may not be considered as an early diagnostic and progression index in CRC. Nevertheless, the decreasing expression tendency of PPAR $\gamma$ found in advanced colorectal cancers in this study may indicate the prognostic potential of PPAR $\gamma$. Furthermore, activation of PPAR $\gamma$ demonstrating an anti-oncogene role in CRC may indicate that although PPAR $\gamma$ was expressed equally in benign tissues and cancer cells of the colorectum, PPAR $\gamma$ activity may decrease in malignant tissues through several pathways such as mutation, post-translational modification, competitive inhibition of PPAR $\beta / \delta$ and decreasing of the endogenic ligands $(20,21)$. Therefore, the specific role of PPAR $\gamma$ in the development and progression of $\mathrm{CRC}$ requires additional studies.

As a tumor suppressor gene, PTEN on chromosome $10 q 23.3$ encodes a dual-specificity phosphatase that negatively regulates the phosphoinositol-3-kinase/Akt pathway and mediates cell-cycle arrest and apoptosis. Several studies have revealed that PTEN aberration is involved in the development of a number of types of cancer $(22,23)$. One study also found that PTEN is involved in CRC (24). However, Zhou et al (25) revealed that distinct PTEN aberrations may occur in variant genetic backgrounds. Furthermore, it was found that the mutation in the ATP motif of PTEN may affect its subcelluar localization and tumor suppressive function $(11,26)$. In our study, PTEN protein was mostly expressed in the cytoplasm, but not in the nucleus, and no significant difference was observed between CRC, adenoma and normal colorectal mucosa, which was consistent with previous studies $(27,28)$. However, whether the unmatched paired design and different genetic backgrounds were responsible for the results requires additional studies. Notably, the correlations between PTEN expression and histological grade or distant metastasis were also noted in CRC tissues, which demonstrated that deletion or low expression of PTEN may not play a role in the primary stage of malignant transformation but may be involved elsewhere in the progression of cancer, such as aggravation of malignant differentiation and metastasis. Based on our present results, PTEN expression may not be a marker for early diagnosis of CRC but may have some potential to predict malignant aggravation and distant metastasis and may also be a potential prognostic marker in $\mathrm{CRC}$, which requires verification by future predictive or prognostic statistical analyses. Moreover, the positive correlation between the expression of PPAR $\gamma$ and PTEN observed in our study may indicate the modulation relationship of these two proteins during colorectal carcinogenesis, which provides additional evidence to support the hypothesis that PTEN may be a downstream regulatory factor of PPAR $\gamma$.

In this study, we elevated efficiency and reduced cost and labor in studies of target gene expression through the use of TMA, a new molecular biotechnology, when compared with immunostaining of conventional specimens. The cell morphology and protein expressions were studied in parallel and the variance in results under various experimental conditions currently experienced with conventional technology may be avoided. Therefore, it is feasible that CRC may be studied using TMA in combination with other molecular biotechnology in the near future. TMA technology, which is fast, convenient and economical, may have a potentially dominant position in macro-scale examination of tissue specimens.

\section{Acknowledgements}

This work is supported by the 135 Medical Important Talent Foundation of Jiangsu Province, China (No.37RC2002037) and the National 863 Project about Functional Genomic and Biochip (No. 2002AA2Z2021).

\section{References}

1. Jemal A, Siegel R, Ward E, Hao Y, Xu J and Thun MJ: Cancer Statistics 2009. CA Cancer J Clin 59: 1-25, 2009.

2. Hung KE and Chung DC: New insights into the molecular pathogenesis of colorectal cancer. Drug Discov Today Dis Mech 3: 439-445, 2006.

3. Glass CK and Rosenfeld MG: The coregulator exchange in transcriptional functions of nuclear receptors. Genes Dev 14: 121-141, 2000.

4. Kliewer SA, Sundseth SS, Jones SA. Brown PJ, Wisely GB, Koble CS, Devchand P, Wahli W, Willson TM, Lenhard JM and Lehmann JM: Fatty acids and eicosanoids regulate gene expression through direct interactions with peroxisome proliferator-activated receptors alpha and gamma. PNAS 94: 4318-4323, 1997

5. Matthiessen MW, Pedersen G, Albrektsen T, Adamsen S, Fleckner J and Brynskov J: Peroxisome proliferator-activated receptor expression and activation in normal human colonic epithelial cells and tubular adenomas. Scand J Gastroenterol 40: 198-205, 2005.

6. Su WD, Bush CR, Necela BM, Calcagno SR, Murray NR, Fields AP and Thompson EA: Differential expression,distribution, and function of PPAR $\gamma$ in the proximal and distal colon. Physiol Genomics 30: 342-353, 2007.

7. Schwab M, Reynders V, Loitsch S, Shastri YM, Steinhilber D, Schröder O and Stein J: PPAR $\gamma$ is involved in mesalazine-mediated induction of apoptosis and inhibition of cell growth in colon cancer cells. Carcinogenesis 29: 1407-1414, 2008.

8. Eng C: PTEN: one gene, many syndromes. Hum Mutat 22: 183-198, 2003.

9. Nassif NT, Lobo GP, Wu X, Henderson CJ, Morrison CD, Eng C, Jalaludin B and Segelov E: PTEN mutations are common in sporadic microsatellite stable colorectal cancer. Oncogene 23: 617-628, 2004.

10. Song MS, Salmena L, Carracedo A, Egia A, Lo-Coco F, Teruya-Feldstein J and Pandolfi PP: The deubiquitinylation and localization of PTEN are regulated by a HAUSP-PML network. Nature 455: 813-817, 2008.

11. Lobo GP, Waite KA, Planchon SM, Romigh T, Nassif NT and Eng C: Germline and somatic cancer-associated mutations in the ATP-binding motifs of PTEN influence its subcellular localization and tumor suppressive function. Hum Mol Genet 18: 2851-2862, 2009.

12. Rahman MA, Dhar DK, Yamagicgi E, Maruyama S, Sato T, Hayashi H, Ono T, Yamanoi A, Kohno $\mathrm{H}$ and Nagasue N: Coexpression of inducible nitric oxide synthase and COX-2 in hepatocellular carcinoma and surrounding liver: possible involvement of COX-2 in the angiogenesis of hepatitis C virus-positive cases. Clin Cancer Res 7: 1325-1332, 2001. 
13. Nagata D, Yoshihiro H, Nakanishi M, Naruyama H, Okada S, Ando R, Tozawa $\mathrm{K}$ and Kohri K: Peroxisome proliferator-activated receptor-gamma and growth inhibition by its ligands in prostate cancer. Cancer Detect Prev 32: 259-66, 2008.

14. Sato H, Ishihara S, Kawashima K, Moriyama N, Suetsugu H, Kazumori H, Okuyama T, Rumi MA, Fukuda R, Nagasue N and Kinoshita Y: Expression of peroxisome proliferator-activated receptor (PPAR) $\gamma$ in gastric cancer and inhibitory effects of PPAR $\gamma$ agonists. Br J Cancer 83: 1394-1400, 2000.

15. Sun WH, Chen GS, Ou XL, Yang Y, Luo C, Zhang Y, Shao Y, $\mathrm{Xu} \mathrm{HC}$, Xiao B, Xue YP, et al: Inhibition of COX-2 and activation of peroxisome proliferator-activated receptor gamma synergistically inhibits proliferation and induces apoptosis of human pancreatic carcinoma cells. Cancer Lett 275: 247-255, 2009.

16. Chen D, Jin GF, Wang Y, Wang H, Liu H, Liu Y, Fan W, Ma H, Miao R, Hu Z, et al: Genetic variants in peroxisome proliferator-activated receptor- $\gamma$ gene are associated with risk of lung cancer in a Chinese population. Carcinogenesis 29: 342-350, 2008

17. Mansen A, Guardiola-Diaz H, Rafter J, Branting C and Gustafsson JA: Expression of the peroxisome proliferators-activated receptor (PPAR) in the mouce colonic mucosa. Biochem Biophys Res Commun 222: 844-851, 1996.

18. Fujisawa T, Nakajima A, Fujisawa N, Takahashi H, Ikeda I, Tomimoto A, Yonemitsu K, Nakajima N, Kudo C, Wada K, et al: Peroxisome proliferator-activated receptor gamma (PPARgamma) suppresses colonic epithelial cell turnover and colon carcinogenesis through inhibition of the beta-catenin/T cell factor (TCF) pathway. J Pharmacol Sci 106: 627-38, 2008.

19. Eun CS, Han DS, Lee SH, Paik CH, Chung YW, Lee J and Hahm JS: Attenuation of colonic inflammation by PPAR $\gamma$ in intestinal epithelial cells: effect on toll-like receptor pathway. Dig Dis Sci 51: 693-697, 2006.

20. Feilchenfeldt J, Brundler MA, Soravia C, Totsch M and Meier CA: Peroxisome proliferators-activated receptors (PPARs) and associated transcription factors in colon cancer: reduced expression of PPARgamma-coactivator 1 (PGC-1). Cancer Lett 203: 25-33, 2004.
21. Hisatake J, Ikezoe T, Carey M, Holden S, Tomoyasu S, and Koeffler HP: Down-regulation of prostate-specific antigen expression by ligands for peroxisome proliferator-activated receptor gamma (troglitazone) in human prostate cancer. Cancer Res 19: 5494-5498, 2000.

22. Puzio-Kuter AM, Martin MC, Kinkade CW, Wang X, Shen TH, Matos T, Shen MM, Cordon-Cardo C and Abate-Shen C: Inactivation of p53 and Pten promotes invasive bladder cancer. Genes and Dev 23: 675-680, 2009.

23. Iwanaga K, Yang YN, Raso MG, Ma L, Hanna AE, Thilaganathan N, Moghaddam S, Evans CM, Li H, Cai WW, et al: Pten inactivation accelerates oncogenic K-ras-initiated tumorigenesis in a mouse model of lung cancer. Cancer Res 68: 1119-1127, 2008.

24. Loupakis F, Pollina L, Stasi I, Ruzzo A, Scartozzi M, Santini D, Masi G, Graziano F, Cremolini C, Rulli E, et al: PTEN expression and KRAS mutations on primary tumors and metastases in the prediction of benefit from cetuximab plus irinotecan for patients with metastatic colorectal cancer. J Clin Oncol 27: 2622-2629, 2009.

25. Zhou XP, Loukola A, Salovaara R, Nystrom-Lahti M, Peltomaki P, De la Chapelle A, Aaltonen LA and Eng C: PTEN mutational spectra expression levels and subcellular localization in microsatellite stable and unstable colorectal cancers. Am J Pathol 161: 439-447, 2002.

26. Lobo GP, Waite KA, Planchon SM, Romigh T, Houghton JA and Eng C: ATP modulates PTEN subcellular localization in multiple cancer cell lines. Hum Mol Genet 17: 2877-2885, 2008.

27. Bowen KA, Doan HQ, Zhou BP, Wang Q, Zhu Y, Rychahou PG and Evers BM: PTEN loss induces epithelial-mesenchymal transition in human colon cancer cells. Anticancer Res 29: 4439-4449, 2009.

28. Rychahou PG, Kang JH, Gulhati P, Doan HQ, Chen LA, Xiao SY, Chung DH, and Evers BM: Akt2 over expression plays a critical role in the establishment of colorectal cancer metastasis. PNAS 105: 20315-20320, 2008. 